\title{
Return Migration: Theory and Empirical Evidence from the UK
}

\author{
Christian Dustmann and Yoram Weiss
}

\begin{abstract}
In this article, we discuss forms of migration that are non-permanent. We focus on temporary migrations where the decision to return is taken by the immigrant. These migrations are likely to be frequent, and we provide some evidence for the $U K$. We then develop a simple model that rationalizes the decision of a migrant to return to his/her home country, despite a persistently higher wage in the host country. We consider three motives for a temporary migration: (i) differences in relative prices between host and home country, (ii) complementarities between consumption and the location where consumption takes place, and (iii) the possibility of accumulating human capital abroad, which enhances the immigrant's earnings potential back home. For the last return motive, we discuss extensions that allow for immigrant heterogeneity, and develop implications for selective in- and out-migration.
\end{abstract}

\section{Introduction}

Much of the theoretical and empirical literature on the economics of migration views migrations as permanent. This is a convenient assumption and facilitates analysis in many areas, such as immigrant behaviour, and the impact of migration on residents' outcomes. We argue in this article that many (and perhaps the majority) of migrations are temporary rather than permanent. This may result in misleading conclusions in analysis that assumes migrations as permanent. One reason is selective out-migration, which may lead to misleading conclusions about economic performance of entry cohorts. Borjas $(1985,1987)$ shows that immigrants may be nonrandomly drawn from the skill distribution in their home countries and that this has important implications for studying immigrants' earnings assimilation. Similarly, out-migration may again be selective (see Borjas and Bratsberg 1996). This in turn may have important consequences for the estimation of performance profiles of immigrants. ${ }^{1}$

Christian Dustmann is at University College London and the Centre for Research and Analysis of Migration (CREAM). Yoram Weiss is at Tel Aviv University. 
A further reason is that assuming permanency neglects an important source of variation explaining heterogeneity in behaviour across immigrants. For instance, when studying human capital investment of individuals and its derivatives (like earnings functions), the literature usually neglects macro conditions, as these are the same for all agents in a particular country. However, when considering immigrants, and if migrations are temporary, this assumption is not valid: current decisions of immigrants who plan to return to their home countries (e.g. on human capital investments) will be based not only on immediate and future circumstances in the host economy, but also on expected future returns in the country of origin. Both these reasons add considerable complexity to modelling the behaviour of immigrants and introduce differences in behaviour between immigrants and natives who are otherwise identical, as well as between (otherwise identical) immigrants of different origin and with different migration durations.

We believe that distinction between permanent and temporary migration is key for understanding many aspects of immigrant behaviour. We commence by providing some discussion and definition of some of the forms of migration that are frequent. We then provide evidence for the temporary nature of migrations, and we choose the UK as an example. Using data from the British Labour Force Survey (LFS), we illustrate that many migrants return back home, and this happens mainly during the first half decade of being in the host country. We also show that return propensities differ across different immigrant communities and between immigrants of different ethnicities. Then, in the simplest possible model, we model a number of reasons why immigrants may want to return back home. We then illustrate how this simple model can be extended, by introducing heterogeneity across immigrants, and how such a framework helps understanding of selective in- and out-migration. We conclude with a discussion as to how consideration of return migrations can explain various aspects of immigrant behaviour.

\section{Forms of migration}

Migrations may take many different forms. A rough classification of forms of migrations is provided in Figure 1. In the figure, we have drawn a first distinction between economic motives for migration and motives related to natural disaster or persecution. Throughout human history, these are the two main reasons why individuals migrate. Receiving countries today draw a distinction between migrations that are due to these two different motivations, and have different arrangements in place for refugees (or asylum seekers) and economic migrants.

Migrations that are due to economic motives may again take different forms, and in the figure, we distinguish on the next level between temporary migrations and permanent migrations. We draw this categorization from the perspective of the receiving country: a migrant is a temporary migrant if he/she stays in a particular country for a limited period of time. ${ }^{2}$ At the same

(C) Blackwell Publishing Ltd/London School of Economics 2007. 
FIGURE 1

Forms of Migration.

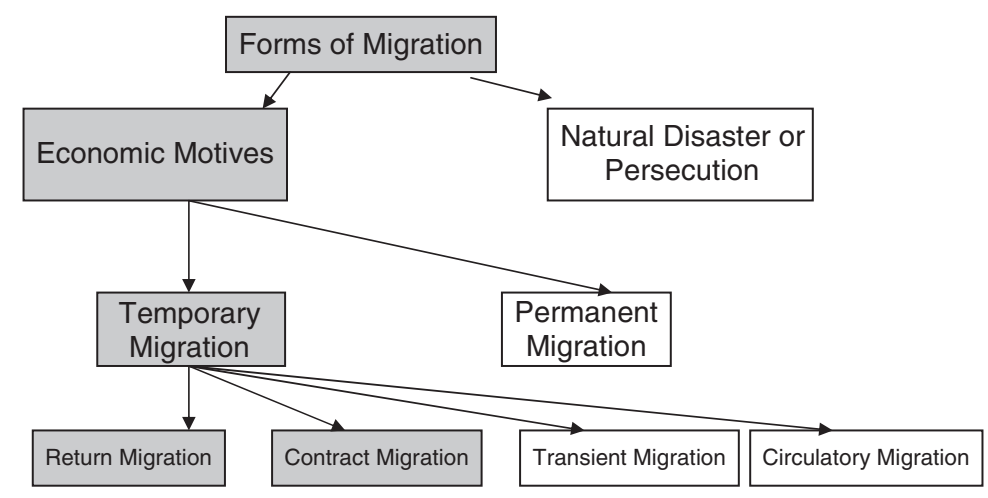

time, the migration may be permanent from the perspective of the immigrant - he/she may leave the home country permanently, but remain temporarily in any one host country.

Temporary migration may again be sub-classified. One important type of temporary migration is circulatory migration. With circulatory migration, migrant workers move frequently between the host and the source country. They only stay for a short period in the receiving country, for example, for the harvest season. Circulatory migration is often induced by a seasonal excess demand for labour in the immigration country that cannot be supplied by the native workforce at adequate prices. In Europe, an example of circulatory migrations is harvest workers from Eastern Europe to Germany, or from Northern Africa to Southern Italy.

A transient migration describes a situation where the migrant moves across different host countries before possibly reaching a final destination. Transient migrations were frequent during the 1960s and 1970s, where migrants from Southern European countries moved between Northern European countries. More recently, an increasing number of (often illegal) immigrants from Africa or Asia enter Europe through Italy, Spain or Portugal and then move to Northern countries such as Germany, the UK or Sweden. ${ }^{3}$

A contract migration is a temporary migration where the migrant lives in the host country for a limited number of years, and where the length of the migration is exogenously determined by, for instance, a residence permit, or a working contract. Labour migrations to Switzerland, for instance, were predominantly designed to be contract migrations. Most migrations into oil-producing countries in the Middle East from Asia, Europe and other Middle East countries are contract migrations.

Return migration is the type of migration one usually has in mind when referring to a migration as being temporary. Return migration describes a situation where migrants return to their country of origin by their own choice, often after a significant period abroad. Many migrations to Europe over the last decades fall into this category. 
This classification is incomplete, and migrations that we observe today take many additional forms. Different combinations between the different types are of course possible. For instance, circulatory migrations are often contract migrations. Although simple, the above classification serves as a convenient framework for the many types of migrations that we observe. In the following discussion, we will focus on one particular type of temporary migration: return migration.

\section{Temporary migrations - some evidence}

How important and how frequent are temporary migrations? Examples of migrations where the migrant chooses the return time (in our definition 'return migrations') are labour migration to Central Europe between 1955 and 1973. Many of these migrants returned back to their home countries. For example, Böhning (1987: 147) estimates that 'more than two thirds of the foreign workers admitted to the Federal Republic [of Germany], and more than four-fifths in the case of Switzerland, have returned'. Glytsos (1988) reports that of the 1 million Greeks migrating to West Germany between 1960 and 1984, 85 per cent gradually returned home. Dustmann (1996) provides additional detail of return behaviour of migrant workers to Germany. Return migration is also important for the United States (see Piore 1979). Jasso and Rosenzweig (1982) report that between 1908 and 1957 about 15.7 million persons immigrated to the United States and about 4.8 million aliens emigrated. They found that between 20 and 50 per cent of legal immigrants (depending on the nationality) re-emigrated from the United States in the 1970s. Warren and Peck (1980) estimate that about one-third of legal immigrants to the United States re-emigrated in the 1960s.

One difficulty with return migration is its measurement. While many countries have registration procedures in place that allow assessment of the number of incoming immigrants, estimation of outflows of immigrants is less straightforward. There are typically no procedures in place that register immigrants who leave a country.

One way to assess the degree of out-migration is to use census or survey information that records the year of arrival. Suppose, for instance, that a representative data set is available that records foreign-born status of individuals as well as (for foreign-born individuals) the year of arrival. Then one could in principle construct for each year the percentage of foreign-born workers who arrived at a particular date within the survey window and who are still in the host country after a given number of years. ${ }^{4}$

To obtain some indication about the temporary character of immigration to the UK, we follow this procedure and use the LFS for the period between 1992 and 2004. The LFS is a survey of private households living in Great Britain. Since the spring quarter 1992, the survey has been conducted each quarter and changed to a rotating panel, with individuals included in five consecutive waves of the survey. The LFS reports for foreign-born individuals the year of arrival. 
We select a sample of foreign-born individuals who report first arrival in 1992 or after. To avoid individuals who came as children or students, we restrict our sample to those whose age at first arrival is 25 years or more. For each arrival cohort, we then construct a measure of the percentage of individuals who are still in the country after up to 10 years. We exclude the year of arrival from our calculations, as there may be problems for the LFS to pick up individuals who have just arrived, or arrival may have been before the survey date in a particular year. Our reference year is thus the first year after arrival. This may result in an underestimate of the extent of return migration, as we do not capture migrations that last less than one year.

For each arrival cohort, we then measure the (weighted) number of foreign-born individuals in Britain in 1993, 1994 and so on, and compute the fraction of individuals still resident in year 2, 3 up to 10 years after arrival, where, as mentioned earlier, year 1 after arrival serves as the base year. We average these fractions for arrival cohorts 1992-2002 to avoid the problem of small sample sizes.

Although this procedure should in principle give us some indication of the degree of return migration, there are multiple sources of error. First, the sample size of the accumulated samples for each year in the LFS changes slightly. Although we weight our observations with population weights, the construction of weights in the LFS does not use immigrant status, so that we may not be able to precisely counteract possible fluctuations in the size of the LFS over the years. Second, and perhaps more important, the years since arrival measures the year of first arrival. It is not unlikely that many foreignborn individuals leave Britain again for some time and then return some years later. If this pattern is not symmetric over the years since arrival distribution, then this may lead to fluctuation in our survival measure. There are other problems that may affect our estimates, such as possible differential non-response of immigrants. Despite these shortcomings, this exercise should give some interesting insight into return migration patterns for different immigrant populations in Britain.

Next we will distinguish between male and female immigrants, as well as between immigrants of different origin and ethnicity. In particular, we distinguish between four groups: immigrants from Europe, the Americas and Australasia; immigrants from Africa; immigrants from the Indian SubContinent; and immigrants from the Middle East, the remainder of Asia and other countries. Further, we distinguish between white and ethnic minority immigrants.

In Table 1 we show the total number of individuals of each of these origin groups and their percentages one year after arrival in the UK. These numbers can be interpreted as a breakdown of the origin composition of new immigrant arrivals in the UK. The largest group are immigrants from Europe, the Americas and Australasia, with one in two new arrivals coming from these origins. Nine in ten immigrants in this category are white. About 18 per cent of new arrivals are from the African Continent. Interestingly, about half of these immigrants are white. These could be from South Africa and from 
TABLE 1

Foreign Born Composition One Year after Arrival

\begin{tabular}{|c|c|c|c|c|c|c|}
\hline & \multicolumn{2}{|l|}{ All } & \multicolumn{2}{|c|}{ Non-White } & \multicolumn{2}{|c|}{ White } \\
\hline & $\begin{array}{l}\text { Number of } \\
\text { observations }\end{array}$ & $\%$ & $\begin{array}{l}\text { Number of } \\
\text { observations }\end{array}$ & $\%$ & $\begin{array}{l}\text { Number of } \\
\text { observations }\end{array}$ & $\%$ \\
\hline $\begin{array}{l}\text { Europe, } \\
\text { Americas, } \\
\text { Australasia }\end{array}$ & 5,550 & 50.74 & 528 & 10.41 & 5,022 & 85.58 \\
\hline Africa & 1,956 & 17.88 & 1,309 & 25.81 & 647 & 11.02 \\
\hline $\begin{array}{l}\text { Indian } \\
\text { Sub-Continent }\end{array}$ & 1,263 & 11.55 & 1,251 & 24.67 & 12 & 0.20 \\
\hline $\begin{array}{l}\text { Middle East, } \\
\text { Remainder of } \\
\text { Asia, other } \\
\text { countries }\end{array}$ & 2,170 & 19.84 & 1,983 & 39.10 & 187 & 3.19 \\
\hline Total & 10,939 & 100.00 & 5,071 & 100.00 & 5,868 & 100.00 \\
\hline
\end{tabular}

Source: British Labour Force Survey, 1992-2004. Males and females, arrival age 25 and above.

FIGURE 2

Migrant Survival, by Gender.
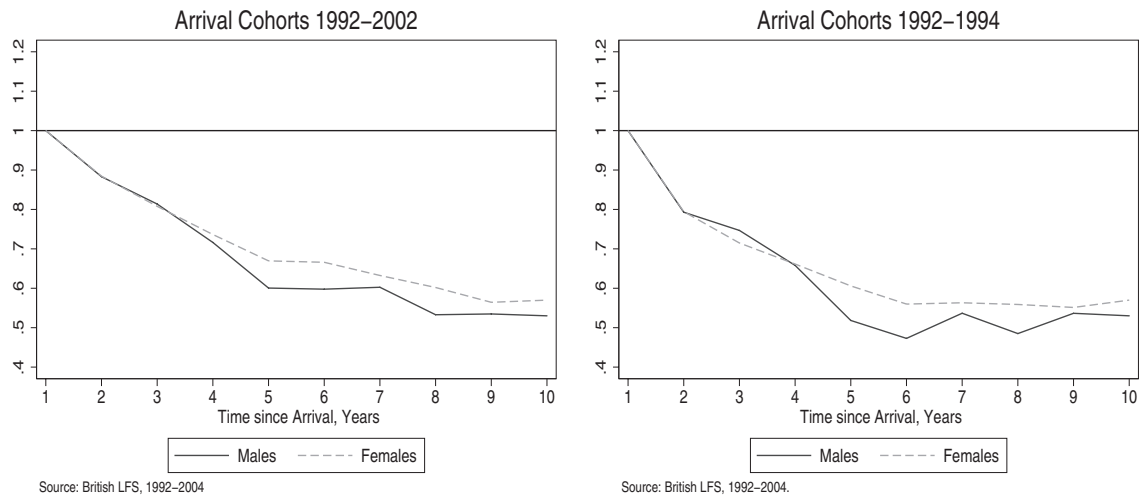

countries where white Africans suffered persecution, such as Zimbabwe. About 12 per cent of immigrant arrivals are from the Indian Sub-Continent, who classify themselves nearly exclusively as non-white. Finally, about 20 per cent of new arrivals are from the Middle East, the remainder of Africa and other countries - with more than 90 per cent in this group being non-white.

In Figure 2, we show the survival rate of immigrants in Britain from the first year after arrival until up to 10 years after arrival. We distinguish in this figure between male (solid line) and female (dashed line) immigrants. In the left panel, we average over all arrival cohorts, as explained earlier. In the right panel, we consider only arrival cohorts between 1992 and 1994.

The graphs suggest that there is a substantial reduction in each entry cohort over time, and the patterns are similar when we use all entry cohorts, 
FIGURE 3

Migrant Survival, by Origin and Ethnicity.
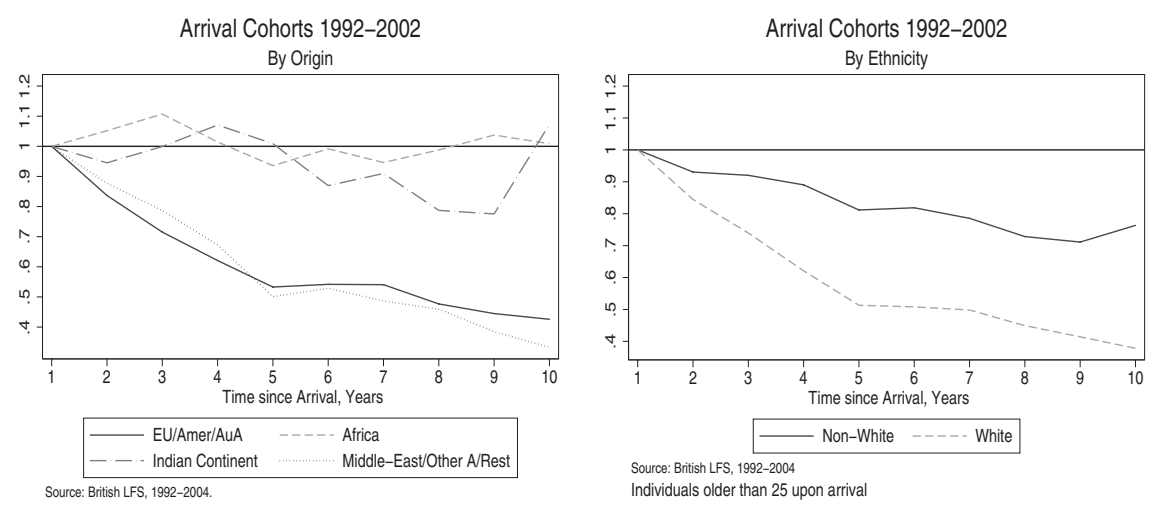

or only those between 1992 and 1994. If we interpret this as return migration, then the largest remigration takes place over the first five years after arrival. Considering all entry cohorts, only about 60 per cent of male and 68 per cent of female foreign born are still in Britain, compared with the population in the first year after arrival. As explained earlier, this is an underestimate for the overall magnitude of return migration, as we do not capture short migrations that do not last longer than one year. After five years, the pattern seems to stabilize. The arrival cohort drops only slightly in size over the next five years. Overall, the extent of remigration seems to be similar for males and females, in particular over the first three to four years; afterwards, females have a slightly lower propensity to leave Britain.

In Figure 3 we pool male and female immigrants but distinguish between origin (left panel) and ethnicity (right panel), where we use the classifications discussed earlier. This figure suggests substantial variation in return propensities across immigrants from different origin countries. While remigration for immigrants from Europe, the Americas and Australasia as well as the Middle East, other Asia and other countries is substantial (more than 45 per cent have returned after five years since arrival, compared with those who are still there after year 1), and seems to continue after five years, return migration for the other two groups is much less pronounced. There is little indication of any return for immigrants from Africa and the Indian Sub-Continent.

The graphs in the right panel pool again male and female immigrants but distinguish between white and non-whites. Again, there are substantial differences between these two groups, with white immigrants having a much higher propensity to return than non-white immigrants: six years after arrival, only about 55 per cent of those who were in Britain one year after arrival are still in the country, with a further decrease to about 40 per cent after ten years. In contrast, the corresponding number for non-whites is about 85 per cent after five years, decreasing to around 80 per cent after ten years. 
These numbers suggest that return migration is quite substantial. Note again that our numbers may underestimate the degree of out-migration, as we are not able to obtain reliable estimates for the number of immigrants in the arrival year, and therefore use year 1 after arrival as the base year. If out-migration during the first year is as substantial as during the second year, then (and considering all immigrants as in the left panel of Figure 2) more than half of all immigrants arriving in the UK will have left the country after six years. Interesting is also the substantial heterogeneity of out-migration according to origin and to ethnicity.

An interesting question is, now who leaves the country, and who stays. Is out-migration positively or negatively selective? This will have important consequences for the overall contribution of immigrants to the British economy; selective out-migration will also affect the estimation of performance measures, such as immigrant assimilation, in straightforward regressions such as in the literature discussed earlier. Ideally, we would want to measure the characteristics of individuals who leave the country after some years and compare these with those who stay. Unfortunately, we do not follow individuals in our data. However, we can compare the average characteristics of entry cohorts of individuals who are observed at different points after arrival. Characteristics that do not change over time, or change in a systematic manner (e.g. age), allow assessment of those who leave and should reveal something about the change in the composition of the immigrant population. Characteristics that may change over the migration cycle do not allow these changes to be allocated to selective out-migration or to adaptation.

In Table 2 we present a number of characteristics for the arrival cohorts 1992-1994, where we consider those still resident at one, five and ten years after arrival. In the first three rows, we show the average age, the average age at arrival, and the age at which the individual reports to have finished full-time education. Given that we consider only individuals who came to Britain at an age older than 25 years, changes in characteristics (e.g. education) between years may suggest changes in the composition in the immigrant population due to out-migration. In the next five rows we show the fraction employed and the occupational distribution of those who are in work. We classify occupations into high, intermediate and low skilled, as well as farmers or farm workers (which is a very small group), and workers who are employed on their own account (which may include self-employment). We categorize workers into the three occupation categories by first estimating wage regressions for all workers (including the native born) in the LFS over this period, and then allocating occupations to three classes of equal size, according to their rank in the distribution of average wages within these occupations.

In the table, we distinguish between male (upper panel) and female (lower panel) immigrants. We first discuss the white male foreign born. Comparing those who are in the UK one, five and ten years after arrival, it seems that average age is increasing to a lesser extent over the first five years than what we would expect if remigration were random along the age distribution,

(C) Blackwell Publishing Ltd/London School of Economics 2007. 
TABLE 2

Composition of Immigrant Population One, Five and Ten Years after Arrival

\begin{tabular}{|c|c|c|c|c|c|c|}
\hline & \multicolumn{3}{|c|}{ White } & \multicolumn{3}{|c|}{ Non-White } \\
\hline & 1 year & 5 years & 10 years & 1 year & 5 years & 10 years \\
\hline \multicolumn{7}{|l|}{ Males } \\
\hline Age & 34.69 & 36.15 & 43.45 & 34.53 & 37.34 & 41.73 \\
\hline Age finished schooling & 21.76 & 20.93 & 20.20 & 21.79 & 20.43 & 19.17 \\
\hline Age at arrival & 33.69 & 31.15 & 33.45 & 33.53 & 32.34 & 31.73 \\
\hline Employed & 72.91 & 79.43 & 80.00 & 46.63 & 67.43 & 73.40 \\
\hline Occupation, high skilled & 41.09 & 40.65 & 26.20 & 24.29 & 22.60 & 22.84 \\
\hline $\begin{array}{l}\text { Occupation, intermediate } \\
\text { skilled }\end{array}$ & 14.96 & 17.28 & 20.00 & 8.89 & 19.54 & 22.47 \\
\hline Occupation, low skilled & 7.76 & 11.68 & 08.96 & 9.76 & 20.30 & 13.85 \\
\hline $\begin{array}{l}\text { Farmers, own-account } \\
\text { workers }\end{array}$ & 0.56 & 6.54 & 14.48 & 0.86 & 2.68 & 11.98 \\
\hline \multicolumn{7}{|l|}{ Females } \\
\hline Age & 33.85 & 37.36 & 42.34 & 35.05 & 37.50 & 42.01 \\
\hline Age finished schooling & 20.93 & 20.15 & 21.08 & 20.32 & 19.85 & 18.42 \\
\hline Age at arrival & 32.85 & 32.36 & 32.34 & 34.05 & 32.50 & 32.01 \\
\hline Employed & 42.61 & 56.47 & 62.68 & 19.49 & 35.40 & 39.45 \\
\hline Occupation, high skilled & 09.73 & 17.26 & 15.9 & 3.14 & 8.38 & 2.38 \\
\hline $\begin{array}{l}\text { Occupation, intermediate } \\
\text { skilled }\end{array}$ & 23.65 & 25.89 & 34.8 & 8.38 & 12.42 & 20.06 \\
\hline Occupation, low skilled & 6.20 & 11.51 & 6.46 & 6.28 & 13.97 & 15.30 \\
\hline $\begin{array}{l}\text { Farmers, own-account } \\
\text { workers }\end{array}$ & 0.83 & 1.07 & 1.99 & 0.00 & 0.62 & 0.68 \\
\hline
\end{tabular}

Source: British Labour Force Survey, 1992-2004. Males and females, arrival age 25 and above, arrival cohorts 1992-1994.

which suggests that relatively more older workers leave during the first five years; however, over the first ten years, selection according to age seems to be less pronounced. The data also indicate that more educated individuals leave relatively early, with the average number of years of schooling received dropping by about one year over the first half decade.

The next rows in the table look at employment probabilities and occupations, which we classify as explained earlier. The reported occupational distributions are conditional on being employed. The percentage of individuals in employment increases slightly, from about 73 per cent to 79 per cent over the first five years.

Interesting are the data that classify individuals into different occupation groups. Here it seems that, while about 42 per cent of white immigrants are classified in high skilled occupations, this percentage drops to 26 per cent after ten years, where most of the reduction seems to take place during the second half of the decade after arrival. As we would expect that immigrants improve their occupational position over their migration cycle, this suggests out-migration that favours those in the upper part of the skill distribution. On the other hand, the percentage of those in the intermediate category increases slightly, while those classified as low skilled remain roughly stable. The last row reports data on farmers and own-account workers. Farmers or 
farm workers constitute only a very small fraction of this category; it is the number of own-account workers that increases substantially over the decade and roughly in a linear manner. It may well be possible, therefore, that some of the drop in highly skilled workers is explained by this increase.

The data for non-whites are reported in the right panel of the table. Again, we first discuss male immigrants. The average age after ten years is about three years lower than what we would expect based on a random selection, which suggests that there is some tendency for individuals above the mean age to leave the country; this selection on age is slightly more pronounced than for white immigrants, despite the lower overall return propensity (see Figure 3). The drop in education is likewise larger than for whites, with average age at which education has been concluded being two years lower after ten years.

The increase in employment probabilities is quite dramatic for this group: it increases from 47 per cent after one year to 67 per cent after five years to 73 per cent after ten years. This is compatible with adaptation of individuals to the UK labour market, but selective out-migration may well lead these numbers to be either smaller or larger than what pure adaptation may induce. Turning to occupational allocations for those who are in employment, we find that, other than for white immigrants, the percentage of those classified as being in highly skilled occupations drops only slightly; however, the percentage of those with intermediate skills increases sharply. Again, this trend may be due to selective out-migration, selection into employment or adaptation - in the absence of panel data, we are not able to distinguish between these three processes.

\section{Why do migrants return?}

We have illustrated that return migrations are frequent. We will now address what induces an immigrant to return. For that purpose, we will start with a very simple model. The idea is as follows. Suppose the immigrant weights in each period the benefits of remaining a further unit of time abroad against the costs of doing so. He/she will then decide to return home when the benefits of staying abroad are lower than the cost. When does this situation occur? The most important reason for emigration are higher wages in the host economy. This creates additional wealth and allows the migrant to increase lifetime consumption. However, as the marginal utility of wealth decreases, the additional benefit of a unit of time in the host country is lower, the longer the migrant has already stayed abroad (and the more wealth he/she has accumulated). Accordingly, the benefit of migration slowly decreases. This alone does not trigger a return migration, because, whatever the immigrant's wealth, it is always advantageous to remain a further unit in a country that pays a higher wage.

One simple way to model a return migration is to assume that migrants have a preference for consumption in their home country. In such a setting, migrants emigrate because that increases their lifetime wealth (and, therefore, their lifetime consumption). At the same time, consumption abroad creates 
less pleasure than consumption at home. Under plausible assumptions, it is straightforward to show within this model that benefits of migration decrease over the migration cycle, while costs are positive and may increase. This may lead eventually to a return migration. We will now provide a more formal discussion.

No-migration and permanent migration are special cases of this model. For a migration to take place, benefits must initially be higher than costs. Accordingly, if, despite a large wage differential, preferences for consumption in the home country (relative to the host country) are strong, no migration will take place. Permanent migration occurs if at the end of the migrant's lifetime, benefits are still higher than costs. Again, this may depend on the preference of the immigrant for home country consumption. Permanent migrations are therefore a special case of return migrations - they occur when, over an immigrant's lifetime, the benefits of migration (here induced by higher wages) are always larger than the costs (here induced by differences in preferences for consumption).

Locational preferences are only one possible motive that triggers a return migration. There are other reasons why migrants may return, despite a persistently more favourable economic situation in the home country. ${ }^{5}$ One reason that induces a remigration is a higher purchasing power of the host country currency in the home country. Migration is temporary because it allows the migrant to take advantage of high wages abroad and low prices at home.

A further reason for a return relies solely on human capital considerations. If the return on human capital acquired in the host country is higher at home, then this alone may trigger a remigration. One situation where this return motive is important is student migrations. Another situation is migration from countries that are in the process of industrialization. Basic knowledge acquired in the industrialized country about work efficiency, organization at the workplace and so on increases the migrant's productivity only slightly in the host country but may be important and highly valued in the home country.

\section{Return Migration and Optimal Migration Duration}

We will now provide a slightly more formal discussion of these three motives for a return migration (see Dustmann 2003 for a similar model). We will, for simplicity, consider only the case where a potential migrant has two choices: first, whether or not to emigrate, and second, whether or not to return to the home country. For simplicity, we will only consider the productive life of an individual and assume that the individual will continue working after return. Our framework is easily extended to the case where the migrant decides not only about a return but also about possible activities after return in the home country (see Dustmann and Kirchkamp 2002). We will also neglect uncertainty about future wages and assume a world of perfect foresight. Furthermore, we will neglect any cost of migration. 
In what follows, we will use superindices $E$ for wages and consumption in the Emigration country (or source country) and $I$ for the Immigration country (or host country). In our model, time $t$ is continuous. The migrant is offered the option to migrate at time $t=0$, and he/she dies at time $t=T$. For simplicity, we assume that he/she works until the end of life, either in the immigration or in the emigration country. Should the migrant decide to emigrate, he/she chooses whether or not to return, as well as the duration of time in the immigration country, jointly with the optimal flows of consumption at home and abroad, $c^{E}$ and $c^{I}$. Wages in the home and host country are denoted by $w^{I}$ and $w^{E}(h)$, respectively. Here $h$ is the time of duration in the immigration country, and $w^{I}>w^{E}(0)$ and $w^{E}(h)$ is increasing and concave in $h$. These assumptions imply that, at $t=0$, wages in the host country are higher than wages in the home country; further, the migrant's wage in the home country increases with time abroad $h$. This reflects in the simplest possible way the possibility that time spent abroad leads to improvement in skills that are of value in the home country. For simplicity, we assume that the wage the migrant receives in the host country remains constant throughout.

To simplify the analysis, there is no discounting in our model. The migrant's lifetime utility function is given by

$$
J=h v\left(c^{I}\right)+(T-h) \xi v\left(c^{E}\right),
$$

where $v(c)=\frac{c^{1-\alpha}}{1-\alpha}$ is the migrant's utility function, and the parameter $\alpha$ governs the rate at which marginal utility declines with consumption. We assume that $\alpha<1$. The parameter $\xi$ represents the migrant's preference regarding the location at which consumption takes place. We shall assume further that $\xi>1$, so that for the same level of consumption in the two countries, the immigrant has a higher level of utility and a higher marginal utility if he/she consumes in the home country.

The migrant maximizes equation (1) with respect to $c^{E}, c^{I}$ and $h$, subject to the lifetime budget constraint

$$
h c^{I}+(T-h) p c^{E}=h w^{I}+(T-h) w^{E}(h) \equiv Y(h),
$$

where $Y(h)$ is lifetime income and $p$ is the price of consumption in the home country, relative to the host country. If $p<1$, consumption abroad is more costly than consumption at home. Accordingly, $1 / p$ is the purchasing power of the host country currency in the source country. Within this simple setting, remigration may occur for three reasons: (i) a higher preference for consumption at home $(\xi>1)$, (ii) a higher purchasing power of the host country currency at home $(p<1)$, and (iii) because time abroad improves the migrant's earnings capacity at home $\left(\frac{d w^{E}(h)}{d h}>0\right)$.

The maximization can be solved in two stages: the immigrant first chooses a time of departure and then, conditioned on this choice, and the resulting 
lifetime income, consumption levels are chosen. Consumption in the second stage must satisfy the condition that there is no possible gain from transferring resources across countries over the immigrant's life cycle. That is

$$
v^{\prime}\left(c^{I}\right)=\frac{\xi}{p} v^{\prime}\left(c^{E}\right) .
$$

It is seen that the immigrant always consumes more when he/she goes back to the home country, because the marginal utility of consumption there is higher and consumption costs less. For the utility function used here, condition (3) implies that $c^{E}=\kappa c^{I}$, where $\kappa$ is a constant that depends on the parameters $\alpha$, $p$ and $\xi$, such that $p \kappa>\xi \geq 1$.

Condition (3), together with the budget constraint (2), determines the levels of consumption for a given $h$.

$$
\begin{aligned}
c^{I}(h) & =\frac{Y(h)}{h+(T-h) p \kappa}, \\
c^{E}(h) & =\frac{\kappa Y(h)}{h+(T-h) p \kappa} .
\end{aligned}
$$

It is seen that, because $p \kappa>1, c^{E}$ and $c^{I}$ must both rise with $h$ if lifetime income $Y(h)$ rises with $h$. That is, if

$$
Y^{\prime}(h)=w^{I}-w^{E}(h)+(T-h) \frac{d w^{E}(h)}{d h}>0 .
$$

By assumption, lifetime income rises initially because the initial wage of the immigrant is higher in the host country than in the home country (i.e. $\left.w^{I}-w^{E}(0)>0\right)$ and time abroad improves the migrant's earnings capacity at home $\left(\frac{d w^{E}(h)}{d h}>0\right)$. But because staying in the host country raises the wage in the home country, it is possible for lifetime wealth to decrease in $h$ after the immigrant has spent sufficient time in the host country for the wage at home to exceed the wage in the host country $\left(w^{E}(h)>w^{I}\right)$.

We can now turn to the determination of the optimal departure date $h$. Differentiating lifetime utility with respect to $h$ and using the results above, one obtains ${ }^{6}$

$$
\frac{d J}{d h} \equiv \Gamma(h)=\alpha\left[v\left(c^{I}(h)\right)-\xi v\left(c^{E}(h)\right)\right]+v^{\prime}\left(c^{I}(h)\right) Y^{\prime}(h) .
$$

We can see that $h$ affects the immigrant's lifetime utility in two ways: a postponement of the departure time entails a loss of the higher utility which is attainable upon returning home. This loss is represented by the term $\alpha\left[v\left(c^{I}(h)\right)-\xi v\left(c^{E}(h)\right)\right]$. But there is also a potential gain, if staying longer in the host country raises lifetime earnings. This potential gain is represented by 
the term $v^{\prime}\left(c^{I}(h)\right) Y^{\prime}(h)$. An important feature of our model is that as long as staying in the home country increases lifetime wealth the incentive to postpone the return date declines. That is, $Y^{\prime}(h)>0 \Rightarrow \Gamma^{\prime}(h)<0$. The basic reason is that increased wealth reduces the marginal utility from additional wealth and raises the cost of delay in terms of forgone consumption in the home country. ${ }^{7}$

If there is an interior solution for the optimal time of departure, $h^{*}$, such that $0<h^{*}<T$, then it is necessary that $\Gamma\left(h^{*}\right)=0$ and $\Gamma^{\prime}\left(h^{*}\right)<0$. Otherwise, the immigrant would either postpone the departure time or leave earlier. Now, because the cost of delay is always positive, an interior solution that satisfies $\Gamma\left(h^{*}\right)=0$ implies that at the optimal time of departure, $h^{*}$, lifetime wealth must be increasing (i.e. $Y^{\prime}\left(h^{*}\right)>0$ ). In other words, the immigrant leaves (if at all) before his/her lifetime wealth reached the maximal value. It then follows that a slight delay in the departure date beyond $h^{*}$ must increase the utility loss and decrease the utility gain. That is, $\Gamma\left(h^{*}\right)=0 \Rightarrow \Gamma^{\prime}\left(h^{*}\right)<0$, which implies that if an interior solution exists it must be unique.

The model nests the two situations of permanent and no migration: migration is permanent if the difference in costs and benefits is positive for $h \rightarrow T$. This case occurs if there is indifference between consumption abroad and at home, equal purchasing power and no effect of time abroad on migrants' earnings potential at home. Then, over the migrant's life cycle, he/she will always find an additional unit of time in the host country creating a higher marginal utility than if this time was spent abroad and, therefore, the immigrant will never return. Migration never occurs if the difference in the benefit and cost is negative for $h \rightarrow 0$. This may be the case, for instance, if the wage differential is small and individuals have a high preference for consumption at home.

Now consider three scenarios that may all lead to a return migration.

Case 1: Preferences for consumption in the home country, $\xi>1, p=1$, $w^{E}(h)=w^{E}<w^{I}$. In this case, lifetime wealth always rises in $h$ (i.e. $Y^{\prime}(h)>0$ for all $h$ ). Therefore, the difference in the benefit and cost of being abroad decreases over the migration cycle (i.e. $\Gamma^{\prime}(h)<0$ for all $h$ ). This is due to the decreasing utility of wealth, which makes each unit of time in the host country more costly in terms of forgone consumption at home. Remigration takes place when the benefit is equal to the cost. Whether this or a corner solution occurs depends on the relative preference for consumption at home and the size of the wage differential. In the limit, for a very large preference for consumption at home, migration will not occur (because $\Gamma(0)<0$ and thus $\Gamma(h)<0$ for all $h$ ). If, on the other hand, the wage in the host country grows very fast relative to the home country wage, migration will become permanent (i.e. $\Gamma(h)>0$ for all $h$ ). In the intermediate case, we shall have $\Gamma(0)>0$ and $\Gamma(T)<0$ so that a unique interior solution $h^{*}$ exists, whereby the person migrates, then stays in the host country a period $h^{*}$ and then goes back to the home country. Obviously, changes in these parameters affect (in the case of an interior solution) the length of the migration duration. ${ }^{8}$ Finally, this return motive creates a target-saving behaviour in the 
case of an interior solution, with immigrants saving while in the host country, and de-saving after return.

Case 2: Lower purchasing power in the home country, $\xi=1, p<1$, $w^{E}(h)=w^{E}<w^{I}$. In this case, too, $Y^{\prime}(h)>0$ and $\Gamma^{\prime}(h)<0$ for all $h$, so that the formal analysis is the same. However, the reason for a return migration is motivated by higher wages in the host country and lower costs of consumption in the home country. Because wages are higher in immigration countries, non-traded goods and services tend to be more expensive in host than in home countries. Furthermore, migrants often exhibit different consumption habits than natives, which may be due to cultural or religious differences. They may demand goods that need to be imported and are accordingly more expensive. A higher purchasing power of the host country currency in the migrant's home country leads to a lower consumption abroad and higher consumption at home.

Case 3: Accumulation of human capital that is applicable at home, $\xi=1$, $p=1, w^{E}(0)<w^{l}$ and $w^{E}(h)$ increasing and concave. In contrast to the previous two cases, the 'cost' of migration is now equal to zero, as equal preferences for consumption and the same purchasing power lead to indifference between consumption in the home and host country (the first term in equation (6) is equal to zero). The only motivation for immigration is to increase lifetime wealth. Given our assumption, the immigrant always gains initially by staying in the host country, because of the initial wage differential. However, the immigrant will leave at the point at which lifetime wealth is maximized. If this point is achieved within the migrant's lifetime, he/she will return home at time $h^{*}$ at which $Y^{\prime}\left(h^{*}\right)=0$. Otherwise, he/she will stay in the host country forever. An immediate implication is that if the impact on wages in the home country is sufficiently strong, so that $w^{E}(T)>w^{I}$, the immigrant will always return to the home country after having migrated to the host country. Thus, migration and remigration may occur because of the initially negative wage differential, combined with a positive impact of experience acquired abroad on wages at home. Migration in this case is purely an investment decision and solely triggered by the future return to human capital.

Combinations of the different scenarios may now serve to describe specific types of migration. For instance, student migrations are frequently characterized by a negative wage differential (consisting of forgone earnings in the home country and possibly negative earnings abroad (fees, etc.)). However, migration occurs if the return to human capital acquired abroad is sufficiently large over the remaining time in the home country.

\section{Introducing heterogeneity}

In our simple model described in the preceding section, we do not draw any distinction between different types of individuals. All immigrants face exactly the same wages in the immigration and emigration countries. 
However, many problems in the economics of migration arise from heterogeneity and how it relates to the initial migration decision, as well as to return migration. For instance, an important question is whether immigrants are positively or negatively selected, in comparison with the nativeborn population. As pointed out by Borjas (1985), selection can lead to cohort effects in, for instance, simple earnings models. Furthermore, if return migration is substantial (as our data above suggest for the UK), then it is important to understand whether it is selective and in which direction.

We will now consider a simple framework that extends our discussion to the case where there is heterogeneity across immigrants. This discussion draws on Rubinstein and Weiss (2006). ${ }^{9}$ Consider two countries, a potential emigration country $(E)$ and a potential immigration country (country $I$ ). We assume that individuals possess two different skills (e.g. skill 1 and skill 2) and that the overall earning capacity of a worker in each of the two countries is a weighted average of their two skill endowments, where the weight of skill 1 is larger in the receiving country while the weight of skill 2 is larger in the source country. The model allows for human capital accumulation through learning by doing. In each country, a worker can augment both skills via a process of learning by doing but at different rates: skill 1 (the skill which is more valuable in the receiving country) accumulates at a faster rate than skill 2 in country $E$ and the converse holds in country $I$. Thus, the two countries differ in the learning opportunities that they provide as well as in the productive contribution of the two skills. Finally, we recognize that for various reasons, such as frictions and informational deficiencies on the side of employers and immigrants, it is unlikely that when workers move from the country of origin to the receiving country their skills can be immediately put into their most productive use. Instead, immigrants undergo an adaptation process, whereby the wages that they receive for their skills in the host country rise gradually as a function of the time spent in the host country.

This framework allows us to study migration and remigration decisions, as well as issues of selection into and out of the immigration country. Remigration in this framework is created by a process similar to the human capital motive discussed previously. We can define two different situations of transferability of human capital, which we refer to as 'partial transferability' and 'super transferability'. Under partial transferability, work experience in any country has a larger impact on the accumulation of local than foreign human capital. In contrast, under super transferability, work experience acquired in one country has a larger impact on the accumulation of foreign than local human capital - this is in nature not dissimilar to our human capital motive above. It can be shown that if work experience is partially transferable, then any potential migrant who wishes to migrate from country $E$ to country $I$ will aim to do so as early in the life cycle as possible. Furthermore, migration decisions will not be reversed, that is, migration decisions will be permanent. If work experience is super 
transferable, migrations will again take place as early in the life cycle as possible, but there will be a return migration after a finite period of time. The reason is similar to the return motive discussed earlier: under supertransferability, the migrant will accumulate skills that are more productive in the home country at a faster rate than in the home country, so that finally his/her earnings potential is higher back home, despite a higher rate of return in the receiving country.

Turning now to the question who will migrate and who will return, we commence again with the case of partial transferability. In Figure 4 we explain the implications the model has for selection. Remember that there are two skills in the model, skill 1 (which is more productive in the receiving country) and skill 2 (which is more productive in the sending country). Let us measure endowments of skill 2 on the horizontal axis and endowments of skill 1 on the vertical axis. Then, skill endowments of each worker are represented by a point in this graph. For simplicity, assume that individuals are equally distributed on this space and that the distributions of skills in the two countries are the same. The thin line in Figure 4 is the 45-degree line, separating the plane into two regions; above this line we find workers who have a relatively larger endowment of skill 1, and below the line we find workers with a relatively larger amount of skill 2 . The solid line in Figure 4 also distinguishes two regions: all individuals with skill endowments above this line will emigrate while all those with skill endowments below it will stay in the country of origin. As seen, the proportion of workers with skill 1 (which suits country $E$ ) is higher among the migrants than among the non-migrants. Under the assumption of identical skill distributions in the two countries, it also follows that immigrants will have a higher endowment of skill 1 than natives of the receiving country. This selection process may explain why immigrants sometimes overtake

FIGURE 4

Selection. S1, skill 1; S2, skill 2.

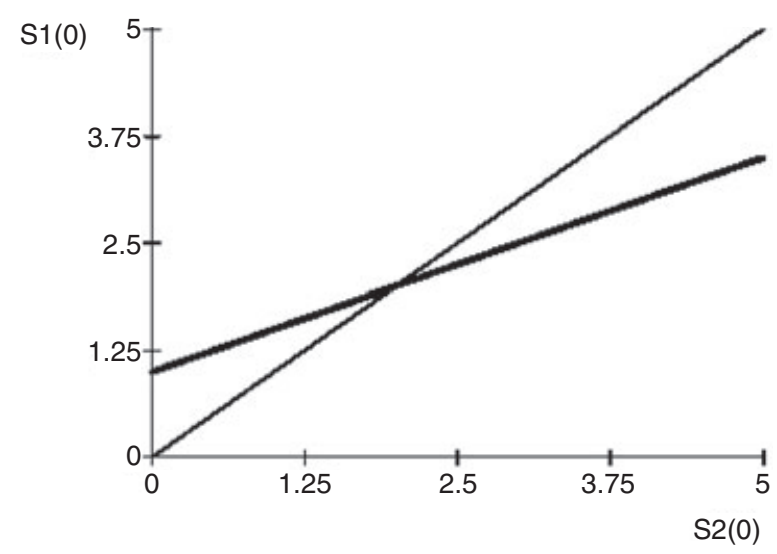

(C) Blackwell Publishing Ltd/London School of Economics 2007. 
natives in terms of wages. This effect is even stronger if we consider the case of super transferability, because then the immigrants who choose to return among those who emigrated have a relatively high endowment of skill 2, which suits country 2 , leaving behind those with an even higher endowment of skill 1 .

\section{Discussion and conclusions}

In this paper, we discuss migrations that are temporary. We illustrate that temporary migrations are frequent. We provide evidence for this from the UK. Our data suggest that, taking the population of immigrants who are still in the country one year after arrival as the base, about 40 per cent of all males and 55 per cent of all females have left Britain five years later. Our data suggest that return migration is particularly pronounced for the group of immigrants from the EU, the Americas and Australia/New Zealand; it is much less pronounced for immigrants from the Indian Sub-Continent and from Africa. Distinguishing between white and non-white immigrants, our data suggest that white immigrants have substantially higher return propensities than non-white immigrants.

We then address the question why immigrants should return. We provide some answers to this question within the simplest possible model and show that return migration may be triggered either by higher preferences for consumption in the home country, or high purchasing power of the host country currency in the migrant's home country, or by accumulation of human capital in the host country in a learning by doing way that improves productivity back home. We show that each of these reasons may lead to a return.

We then extend our argument by introducing heterogeneity of immigrants in terms of their skills. This allows us to study selective in-migration as well as selective out-migration. We have shown that this selection works to generate an immigrant population in the receiving country that has a relatively large endowment of skill 1 (the skill which is more valuable in the immigration country), which is the reason why they choose to enter or stay in the receiving country. Therefore, wage comparison between natives and immigrants in the receiving country are biased in favour of immigrants, which may be one possible reason why immigrants sometimes overtake natives in terms of wages. ${ }^{10}$

What consequences have temporary migrations (as opposed to permanent migrations) for the economic analysis of immigration? A large area in the economics of immigration is concerned with understanding the way immigrants perform in the host country labour market over their life cycle. Typically, this literature assumes that migrations are permanent and estimates Mincer-type earnings functions for immigrants as well as natives, using the time that an immigrant is resident in the destination country as a measure for the accumulation of residence-country specific human capital. If migrations are non-permanent, however, the 'years since migration' measure may relate 
to different populations, with different compositions in observed and unobserved characteristics, except if return migration is random. This induces bias in estimation that is not dissimilar to that of estimates of tenure effects in straightforward regressions. As our analysis in section 2 demonstrates, the sample of immigrants still in the UK after ten years is different in terms of age and education than the sample of immigrants after one year, which may suggest that out-migration is indeed selective. We have taken this up again in our theoretical discussion, where we demonstrate that, within the particular model we discuss, those who remain in the host country are those who have more skills that are usable there. Therefore, if out-migration is selective, estimates of immigrants' performance profiles will be biased, through an overestimate or an underestimate of the effect of the years of residence measure.

Return migration may introduce other types of heterogeneity into immigrant behaviour which we have not addressed in this paper. Apart from being selective, return migration may lead to variation in the incentive structure different immigrants (with different return plans) face, and also lead to heterogeneity between immigrants and otherwise identical natives. The reason is that immigrants who have only temporary intentions to remain in the host country will take into account economic conditions in their home countries after return when making economic decisions in the host country, such as labour supply decisions, saving decisions and decisions about investment in human capital.

The relatively large proportion of immigrants that leave again after the first five years of in-migration is unlikely to be a particular feature of Britain. Also, the substantial heterogeneity across different immigrant groups is not likely to be a particularity for Britain, and similar patterns are likely in other countries. Given the large potential bias that selective out-migration may induce, it is most likely that much of the existing analysis of immigrant behaviour and performance would change, perhaps radically, if we had additional information on return migration. Furthermore, even if out-migration was random, differences in behaviour induced by return plans are an additional source of bias. It seems to us that appropriate assessment of immigrant performance has to take into account return migration and its possible effects on estimation; otherwise, we may rely on possibly greatly distorted assessments of immigrant performance in host economies.

As we have emphasized, return migration also affects the performance of immigrants when they go back home. Indeed, with a sufficiently high rate of return migration, the source country can actually gain from the opportunity that its citizens have to acquire experience abroad - which is quite the opposite of the usual brain-drain argument. An example of this sort could be the large number of young Israeli engineers who went to the United States and the significant proportion of them who returned to create a thriving IT industry in Israel.

Final version accepted on 16 February 2007. 


\section{Acknowledgements}

Christian Dustmann acknowledges support from the Economic and Social Research Council (ESRC) (grant RES-000-23-00332).

\section{Notes}

1. Papers such as Chiswick (1978) and Borjas (1985) for the United States; Baker and Benjamin (1994) for Canada; Friedberg (2000) for Israel; Bell (1997) and Chiswick (1980) for the UK; and Barth et al. (2004) for Norway all implicitly assume migrations as permanent.

2. For many aspects of analysis of immigrant behaviour, it is convenient to define a migration as temporary if the migrant leaves the country before reaching retirement age.

3. Transient migrations are often referred to as chain migrations.

4. Rendall and Ball (2004) follow a similar procedure. They also provide projections on return migration based on the International Passenger Survey. Although they use a different breakdown, their numbers are in line with ours.

5. See Dustmann (2001) for a general framework for investigating return migration and optimal migration durations. In Dustmann (1997), return migration and optimal migration durations are analysed in a stochastic environment.

6. This expression is obtained using the following steps:

$$
\begin{aligned}
\frac{d J}{d h} & =v\left(c^{I}(h)\right)-\xi v\left(c^{E}(h)\right)+h v^{\prime}\left(c^{I}(h)\right) \frac{d c^{I}}{d h}+(T-h) \xi v^{\prime}\left(c^{E}(h)\right) \frac{d c^{E}}{d h} \\
& =v\left(c^{I}(h)\right)-\xi v\left(c^{E}(h)\right)+v^{\prime}\left(c^{I}(h)\right)[h+p(T-h) \kappa] \frac{d c^{I}}{d h} \\
& =v\left(c^{I}(h)\right)-\xi v\left(c^{E}(h)\right)-v^{\prime}\left(c^{I}(h)\right) c^{I}(h)(1-p \kappa)+v^{\prime}\left(c^{I}(h)\right) Y^{\prime}(h) \\
& =v\left(c^{I}(h)\right)-v^{\prime}\left(c^{I}(h)\right) c^{I}(h)-\xi\left[v^{\prime}\left(c^{E}(h)\right)-v^{\prime}\left(c^{E}(h)\right) c^{E}(h)\right]+v^{\prime}\left(c^{I}(h)\right) Y^{\prime}(h) \\
& =\alpha\left[v\left(c^{I}(h)-\xi v\left(c^{E}(h)\right)\right]+v^{\prime}\left(c^{I}(h)\right) Y^{\prime}(h) .\right.
\end{aligned}
$$

7. When $Y^{\prime}(h)>0$, then the term $v\left(c^{I}(h)-\xi v\left(c^{E}(h)\right)\right.$ declines because $v^{\prime}\left(c^{I}(h)\right) \frac{d c^{I}}{d h}-\xi v^{\prime}\left(c^{E}(h)\right) \frac{d c^{E}}{d h}=v^{\prime}\left(c^{I}(h)\right)(1-p \kappa) \frac{d c^{I}}{d h}<0 \quad$ and $\quad$ the term $v^{\prime}\left(c^{I}(h)\right) Y^{\prime}(h)$ declines with $h$ because $v^{\prime \prime}\left(c^{I}(h)\right) \frac{d c^{I}}{d h}<0$ and, by assumption, $Y^{\prime \prime}(h)<0$.

8. Dustmann (2003) shows that in a similar model, an increase in host country wages induces both an income effect and a relative wage effect; while the latter will always lead to an increase in the migration duration, the former leads to a decrease, as the value of staying abroad decreases with lifetime income. The total effect of an increase in host country wages on the total migration duration may be positive or negative.

9. Details and formal analysis are provided in an Appendix available from the authors upon request.

10. However, Eckstein and Weiss (2004) show that even without such a bias it is likely that immigrants will invest at a higher intensity than natives because of a gradual adoption of skills to the host country. Specifically, the opportunity costs are initially low because skills are underutilized, but the future returns are relatively high because with time, job matching improves. 


\section{References}

Baker, M. and Benjamin, D. (1994). 'The performance of immigrants in the Canadian labour market'. Journal of Labor Economics, 12: 369-405.

Barth, E., Bratsberg, B. and Raaum, O. (2004). 'Identifying earnings assimilation of immigrants under changing macroeconomic conditions'. Scandinavian Journal of Economics, 106 (1): 1-22.

Bell, B. D. (1997). 'The performance of immigrants in the United Kingdom: evidence from the GHS'. The Economic Journal, 107 (441): 333-44.

Borjas, G. J. (1985). 'Assimilation, changes in cohort quality, and the earnings of immigrants'. Journal of Labor Economics, 3 (4): 463-89.

- (1987). 'Self-selection and the earnings of immigrants'. American Economic Review, 77 (4): 531-53.

- and Bratsberg, B. (1996). 'Who leaves? The outmigration of the foreign-born'. The Review of Economics and Statistics, 87 (1): 165-76.

Böhning, W. (1987). Studies in International Migration. New York: St. Martin's Press.

Chiswick, B. R. (1978). 'The effect of Americanization on the earnings of foreign-born men'. Journal of Political Economy, 86: 897-921.

— (1980). 'The earnings of white and coloured male immigrants in Britain'. Economica, 47 (185): 81-87.

Dustmann, C. (1996). 'Return migration: the European experience'. Economic Policy, 22: $215-50$.

(1997). 'Return migration, uncertainty and precautionary savings'. Journal of Development Economics, 52 (2): 295-316.

— (2001). 'Return decisions of immigrants'. In S. Djajic (ed.), International Migration: Trends and Policy and Economic Impact. London: Routledge, pp. 229-68.

- (2003). 'Return migration, wage differentials, and the optimal migration duration'. European Economic Review, 47 (2): 353-67.

- and Kirchkamp, O. (2002). 'The optimal migration duration and activity choice after re-migration'. Journal of Development Economics, 67 (2): 351-72.

Eckstein, Z. and Weiss, Y. (2004). 'On the wage growth of immigrants: Israel 1990-2000'. Journal of the European Economic Association, 2: 665-95.

Friedberg, R. M. (2000). 'You can't take it with you? Immigrant assimilation and the portability of human capital'. Journal of Labor Economics, 18 (2): 221-51.

Glytsos, N. P. (1988). 'Remittances and temporary migration: a theoretical model and its testing with the Greek-German experience'. Weltwirtschaftliches Archiv, 124: $524-49$.

Jasso, G. and Rosenzweig, M. R. (1982). 'Estimating the emigration rates of legal immigrants using administrative and survey data: the 1971 cohort of immigrants to the United States'. Demography, 19: 279-90.

Piore, M. J. (1979). Birds of Passage. Cambridge: Cambridge University Press.

Rendall, M. S. and Ball, D. J. (2004). 'Immigration, emigration and the ageing of the overseas born population in the United Kingdom'. Population Trends, 116 (Summer): 18-27.

Rubinstein, Y. and Weiss, Y. (2006). 'Post-schooling wage growth: investment, search and learning'. In E. A. Hanushek and F. Welch (eds.), Handbook of the Economics of Education, vol. 1. Amsterdam: Elsevier, pp. 1-67.

Warren, R. and Peck, J. M. (1980). 'Foreign-born emigration from the United States'. Demography, 17: 71-84. 